\title{
Bottom-hole pressure optimization when operating the well lateral horizontal hole
}

\author{
Rinat Faizullin ${ }^{1, *}$, Sergey Miroshnichenko ${ }^{1}$, and Ravil Sultanov ${ }^{1}$ \\ ${ }^{1}$ Kalashnikov Izhevsk State Technical University, 426069, 30 let Pobedy 2, bld. 5, Izhevsk, Russia
}

\begin{abstract}
The problem of optimization of technological parameters as a way to improve the efficiency of oil deposit exploitation is considered in the paper. There are no standards for parameters of well bottom-hole pressure for exploitation of lateral horizontal holes. The paper presents the evaluation of optimum bottom-hole pressure at which it is advisable to exploit the deposit lateral horizontal hole with maximum "water-free" production rate. Following the calculations carried out and analysis of the graphs of additional oil and liquid production dependence on bottom-hole pressure, graphs of production dynamics and water encroachment, it was concluded that 3 groups of drilling (kickoff) of lateral holes (KLH) should be distinguished: with high forecasted starting water encroachment $(>90 \%)$, average starting water encroachment (about $80 \%$ ), and low starting water encroachment (about 20-50\%). The distinguished 3 groups allow applying the differentiation of parameters, for which optimum bottom-hole pressure parameters for each drilling group were found.
\end{abstract}

\section{Introduction}

The oil well is a complex technical system both in design and processes inside it. It is known that multiphase currents (e.g. during a well startup) can arise in the well hole [1].

The method based on physical mechanics of liquid and modeling numerical methods can be considered a standard approach to modeling the multiphase current in the well hole [2].

Modern investigations often apply computer-aided learning methods to forecast physical parameters of the well hole current with strong multiphase and transition effects [3], to forecast bottom-hole pressure in multiphase current of vertical oil production wells [4].

The possibility of well premature water pumping is basically determined by the distance from the bottom hole to the bottom water face, or to the edge water contour, vertical and horizontal reservoir permeability, degrees of reservoir heterogeneity and well exploitation modes. There is some optimum mode and certain degree of reservoir drilling-in, which allow providing a so-called utmost well water-free production rate [5].

The attention should be drawn to the fact that reservoir permissible drawdown pressure value depends on the properties of fluids, oil-water contact position and drilling-in value,

*Corresponding author: rf85@mail.ru 
i.e. lower boundary of perforation interval, on reservoir vertical permeability and bottom water activity. At present, several methods for determining reservoir permissible drawdown pressure values and utmost water-free production rates have been proposed. All approximate methods recommended by now describe the physical essence of water pumping process rather vaguely, and, in the vast majority of cases, the forecasted waterfree production rates do not coincide with actual reservoirs and water pumping time of wells. The reason of such non-coincidence is a very rough schematization of the water pumping process. Therefore, the design engineer's main task is to evaluate the range of expected production rates and drawdown pressures onto the reservoir with bottom water available.

\section{Materials and methods}

The optimization of technological parameters is necessary for effective exploitation of oil deposits. The optimum parameters of well bottom-hole pressure to exploit lateral horizontal holes are not standardized. The task was to assess at what optimum Pbhp (bottom-hole pressure) it is advisable to exploit LHH (lateral horizontal hole) of XXX deposit with maximum "water-free" production rate. The economic limitation for utmost water encroachment of $98 \%$ was additionally set.

The main investigation tasks were:

1) forecasting of the dynamics of technological indexes of well exploitation distinguished for spudding in lateral holes when designing the reservoir development;

2) selection of the optimum technological operation mode of wells - candidates for spudding in lateral holes;

3) factor analysis of geological and physical conditions influencing the selection of optimum bottom-hole pressure of lateral hole;

4) development of ranging algorithm of well lateral horizontal holes by the criterion determining their optimum exploitation mode.

Investigation methods: analysis of deposit development history, geological and hydrodynamic modeling, methods of oil-and-gas hydromechanics, methods of decisionmaking theory, factor analysis $[7,8,9]$.

\section{Results}

In 2016 the commission of 5 KLH was planned on Tournaisian object of XXX deposit [7]. According to the map, the majority of candidates were in the areas with relatively low residual mobile oil by RGTM (regular geological and technological model).

1. According to the map of residual mobile oil by RGTM, the majority of candidates are in the areas of low residual mobile oil.

2. Based on the calculation results, 3 groups of drilling (kickoff) of lateral holes (KLH) are distinguished: with high forecasted starting water encroachment $(>90 \%)$, average starting water encroachment (about $80 \%$ ), and low starting water encroachment (about 20 $50 \%)$.

KLH group with high forecasted starting water encroachment.

High forecasted starting water encroachment in the range of $90-95 \%$ depending on Pbhp, high starting fluid withdrawal rates of 200-700 m3/day are characteristic for wells $\mathrm{W} 1, \mathrm{~W} 2, \mathrm{~W} 4$. Additional production of oil within 5 years monotonously increases with Pbhp decrease and reaches the maximum value at Pbhp $=30 \mathrm{~atm}$ for wells $\mathrm{W} 1, \mathrm{~W} 4$ and $\mathrm{Pbhp}=50 \mathrm{~atm}$ for W2. 


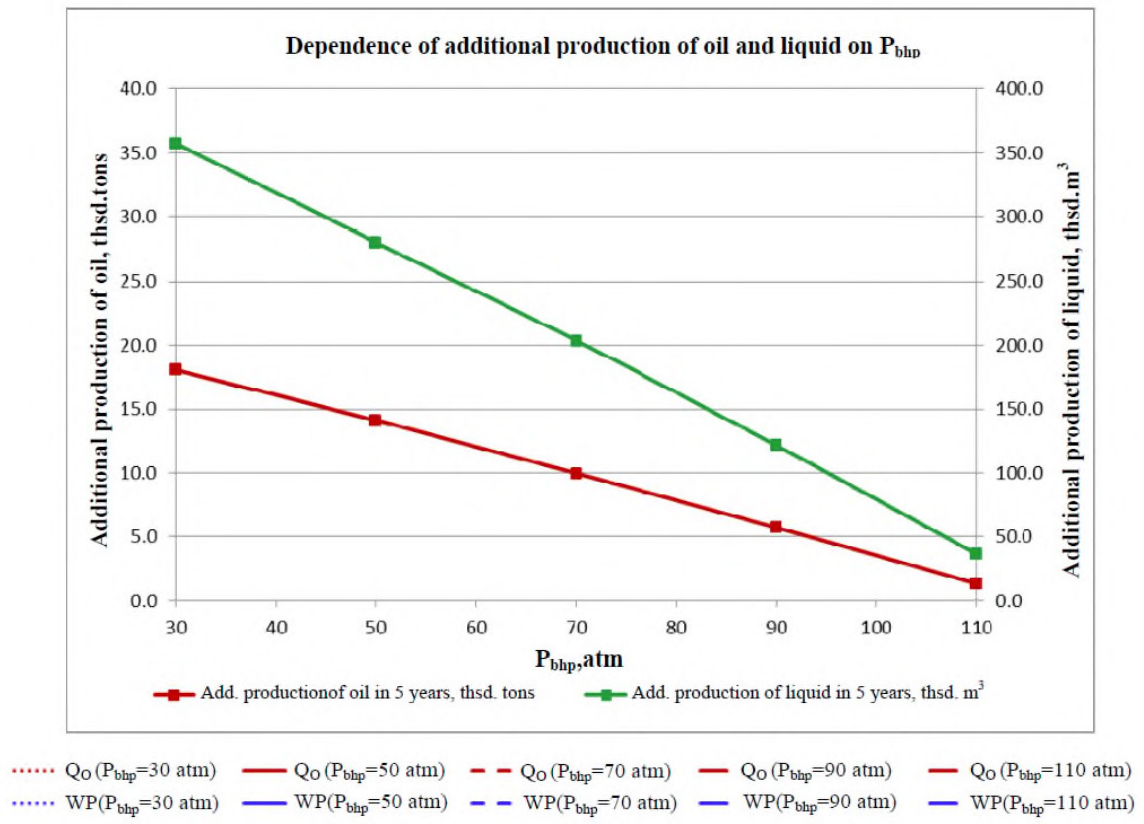

Fig. 1. Dependence of additional production of oil and liquid on Pbhp.

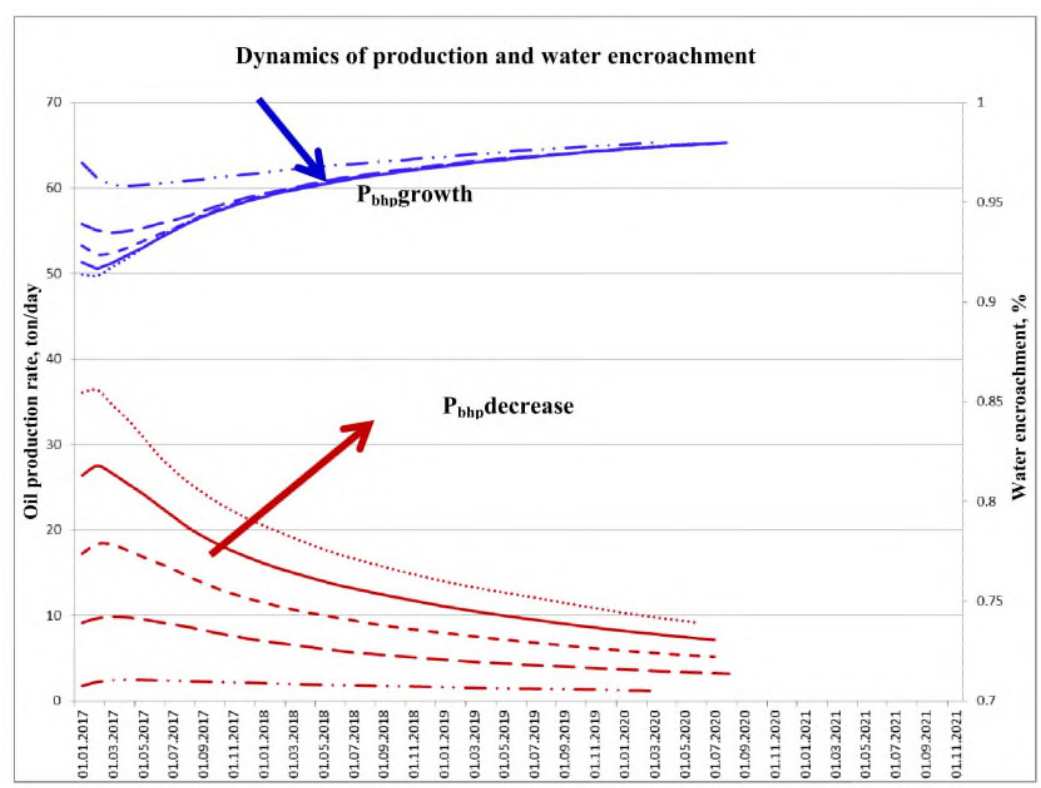

$\cdots \cdot \mathrm{Q}_{0}\left(\mathrm{P}_{\text {bhp }}=30 \mathrm{~atm}\right)-\mathrm{Q}_{0}\left(\mathrm{P}_{\text {bhp }}=50 \mathrm{~atm}\right) \quad-\mathrm{Q}_{\mathrm{O}}\left(\mathrm{P}_{\mathrm{bhp}}=70 \mathrm{~atm}\right)-\mathrm{Q}_{0}\left(\mathrm{P}_{\mathrm{bhp}}=90 \mathrm{~atm}\right) \quad-\mathrm{Q}_{0}\left(\mathrm{P}_{\text {blp }}=110 \mathrm{~atm}\right)$

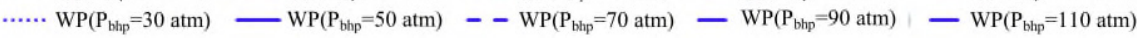

Fig. 2. Dynamics of production and water encroachment.

As seen from the calculations, the maximum oil production rate and, consequently, additional production of oil at the minimum water encroachment are reached at the minimum bottom-hole pressure (30 atm), and monotonously decrease with its growth. 
Tournaisian object. Well No W2

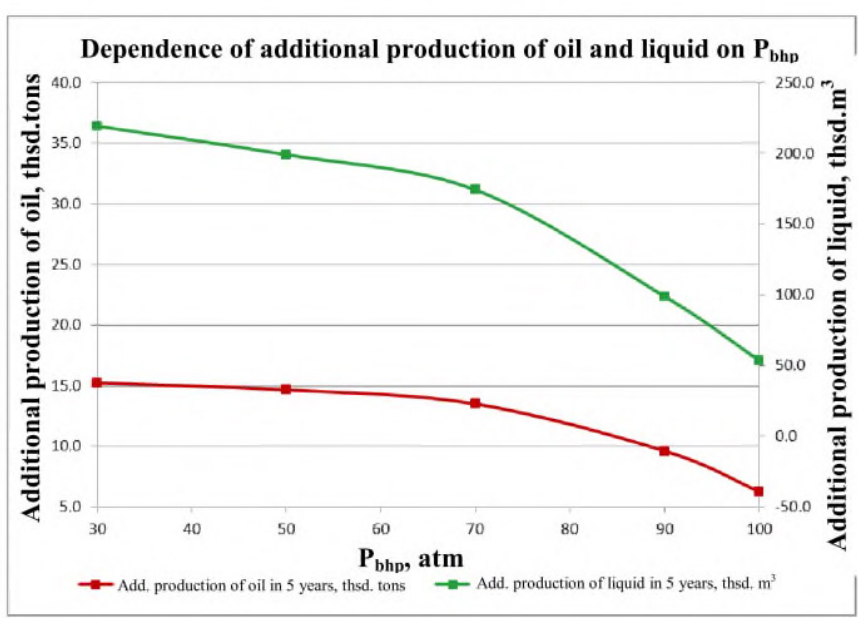

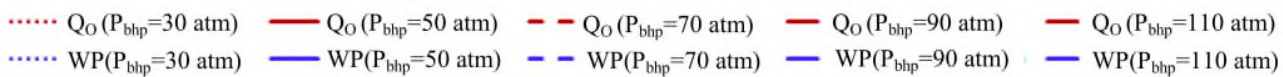

Fig. 3. Dependence of additional production of oil and liquid on Pbhp.

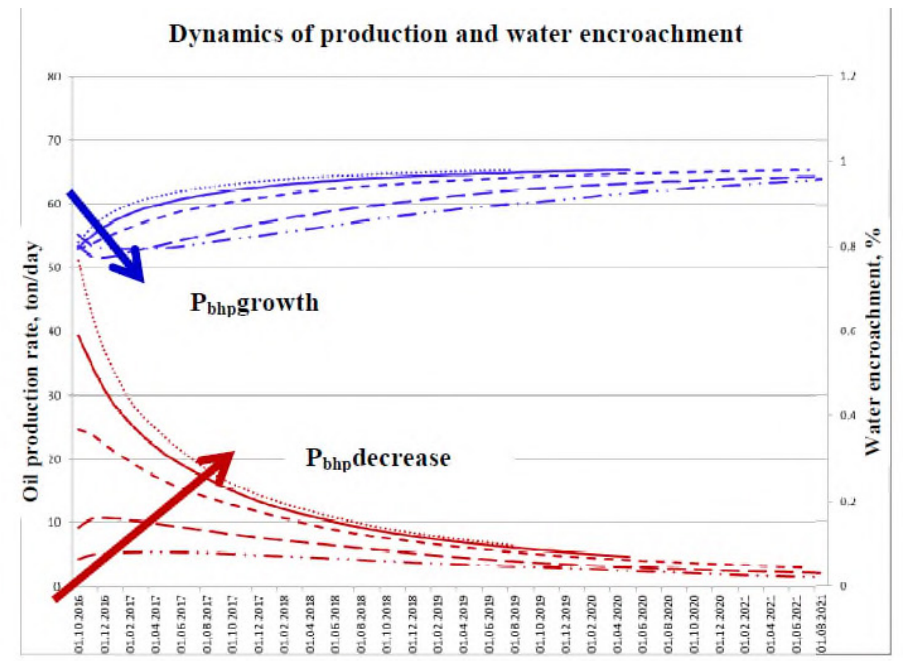

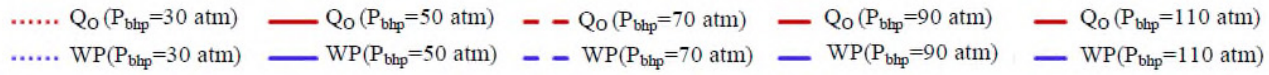

Fig. 4. Dynamics of production and water encroachment.

As seen from the calculations, the maximum oil production rate and, consequently, additional production of oil at the minimum water encroachment are reached within the pressure range of 30-70 atm; with further pressure growth the production drops dramatically. 
Tournaisian object. Well No W3

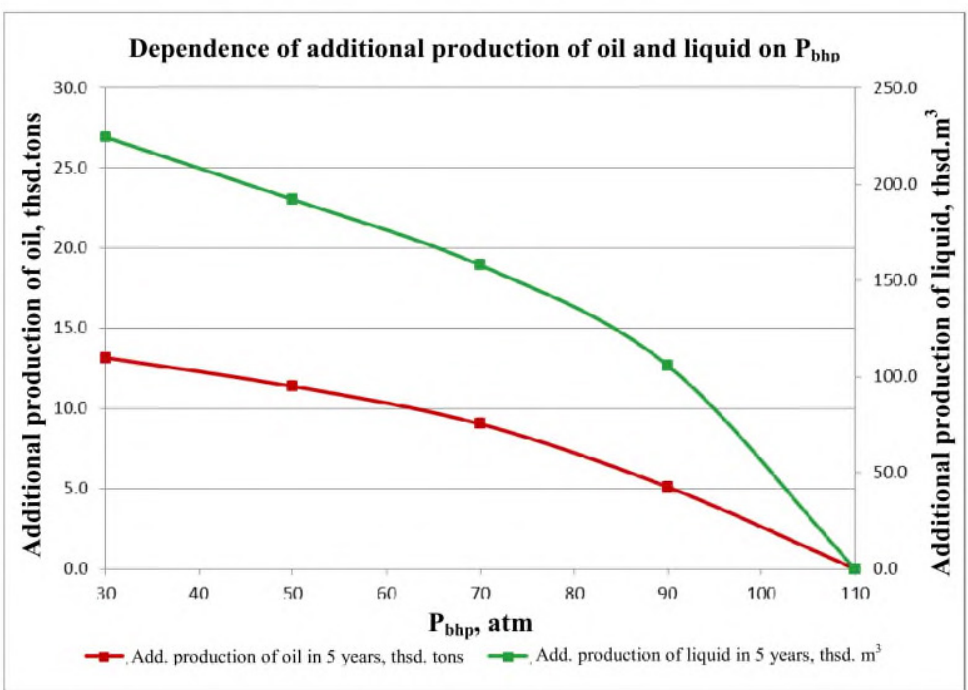

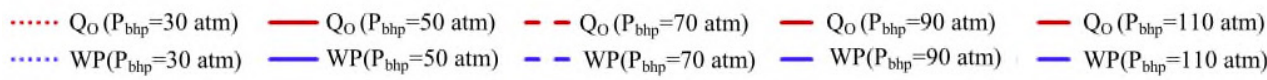

Fig. 5. Dependence of additional production of oil and liquid on Pbhp.

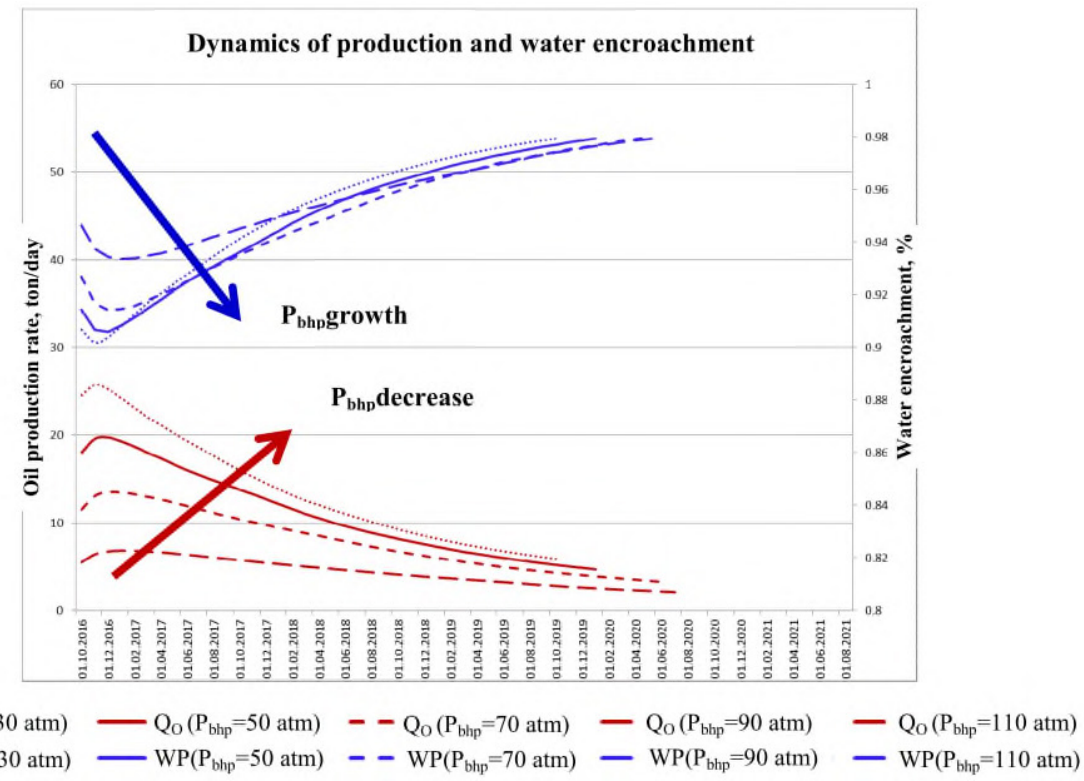

Fig. 6. Dynamics of production and water encroachment.

As seen from the calculations, the maximum oil production rate and, consequently, additional production of oil at the minimum water encroachment are reached at the minimum bottom-hole pressure (30 atm), and monotonously decrease with its growth. 


\section{Tournaisian object. Well No W4}

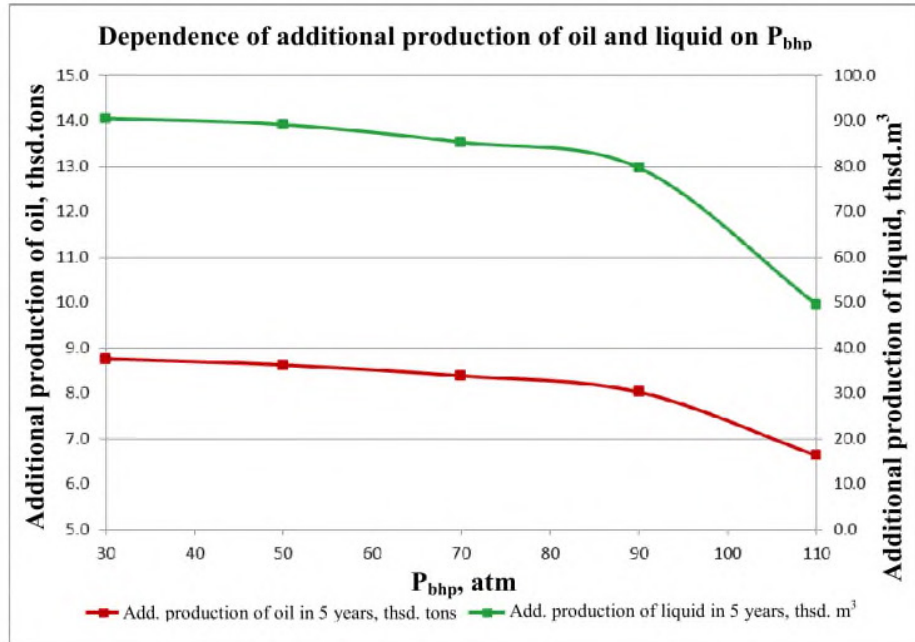

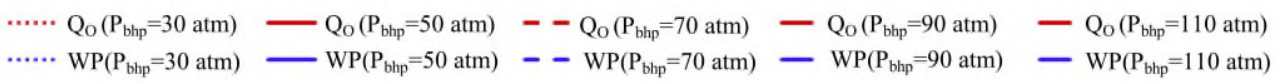

Fig. 7. Dependence of additional production of oil and liquid on Pbhp.

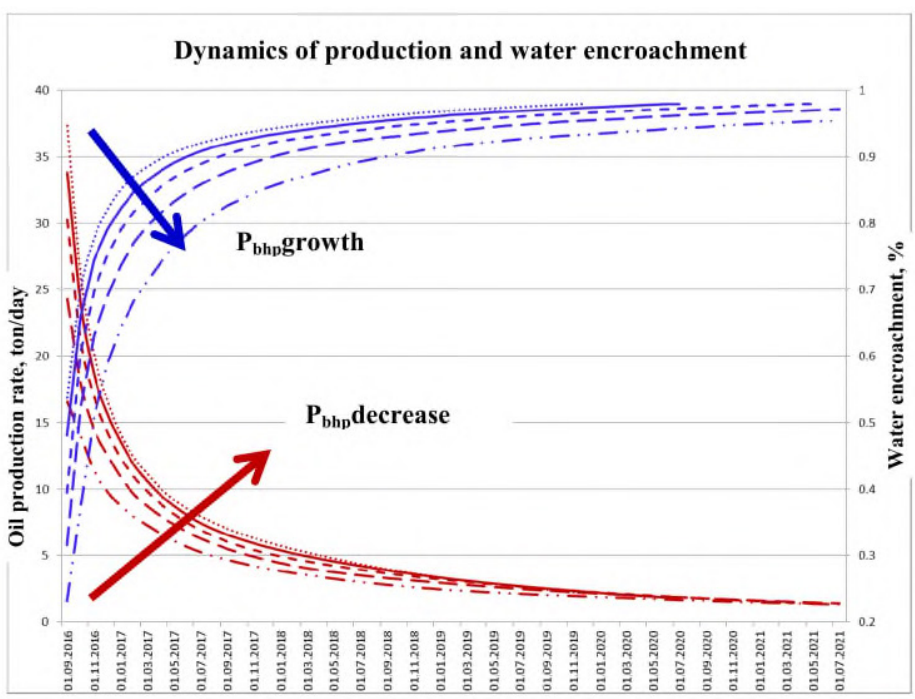

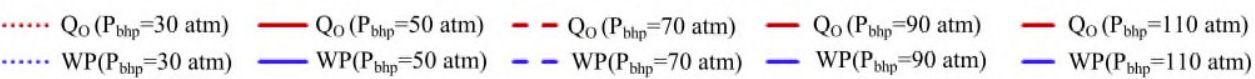

Fig. 8. Dynamics of production and water encroachment.

As seen from the calculations, the maximum oil production rate and, consequently, additional production of oil at the minimum water encroachment are reached within the pressure range of 30-70 atm; with further pressure growth the production drops dramatically. 
Tournaisian object. Well No W5

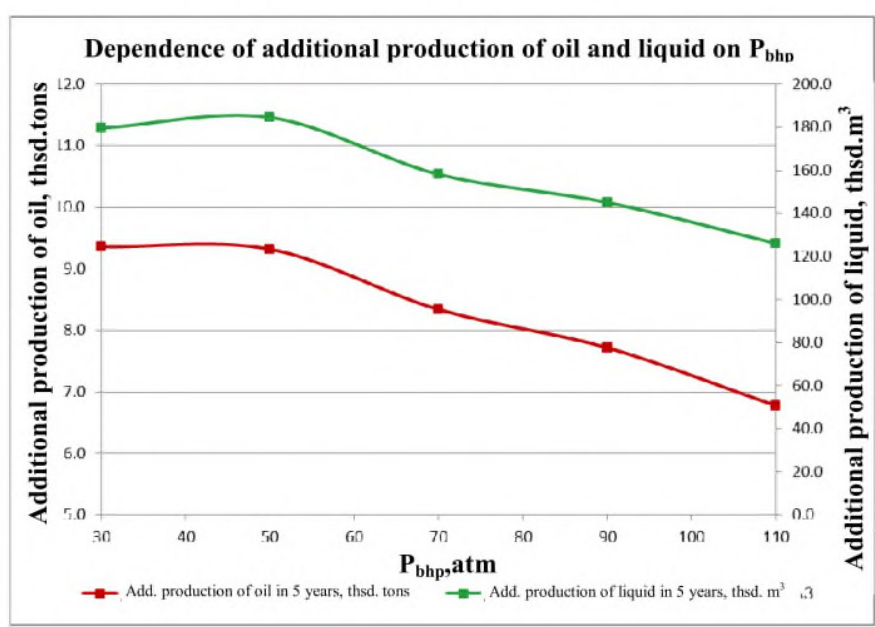

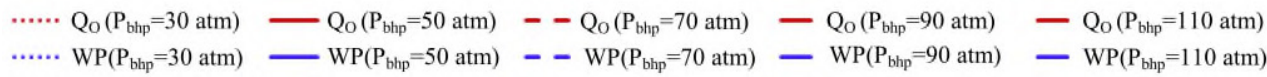

Fig. 9. Dependence of additional production of oil and liquid on Pbhp.

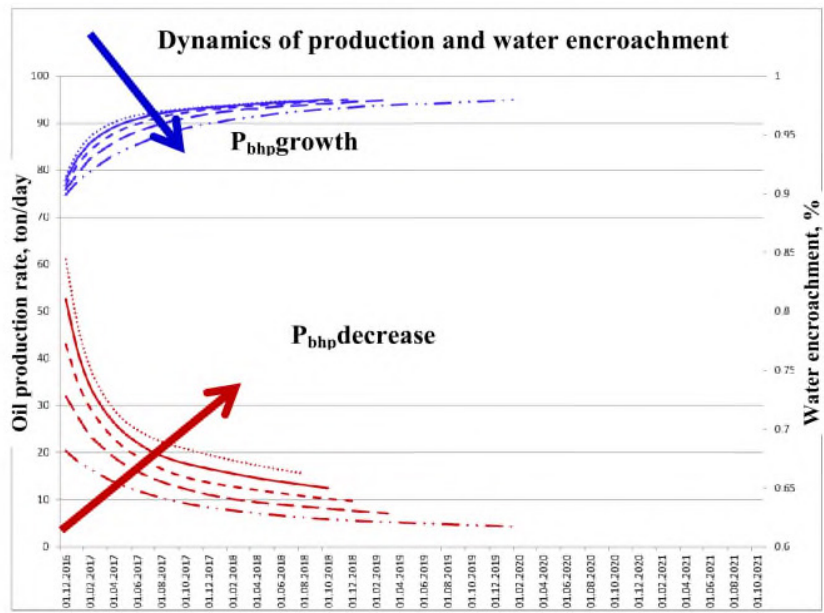

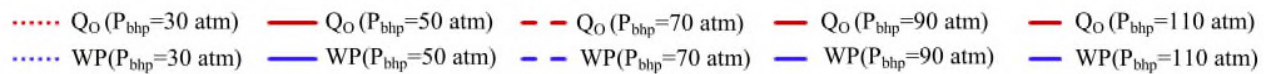

Fig. 10. Dynamics of production and water encroachment.

As seen from the calculations, the maximum oil production rate and, consequently, additional production of oil at the minimum water encroachment are reached within the pressure range of 30-50 atm; with further pressure growth the production goes down.

KLH group with average forecasted starting water encroachment.

For well 5 the forecasted starting liquid withdrawals are in the range of $25-267 \mathrm{~m} 3 /$ day depending on Pbhp at initial water encroachment of $80 \%$. The sharp decrease in additional oil production rate increase within 5 years is observed at Pbhp $\leq 70 \mathrm{~atm}$. To decrease the risks of premature water pumping and negative influence on neighboring producing wells, the targeted $\mathrm{Pbhp}=70 \mathrm{~atm}$ is recommended.

KLH group with low forecasted starting water encroachment. 
For well W3 the forecasted starting liquid withdrawals are in the range of $20-80 \mathrm{~m} 3 /$ day with the starting water encroachment in the range of $20-50 \%$ depending on Pbhp. The sharp decrease in additional oil production rate increase within 5 years is observed at Pbhp $\leq 90$ atm. To decrease the risks of premature water pumping and negative influence on neighboring producing wells, the targeted $\mathrm{Pbhp}=90 \mathrm{~atm}$ is recommended.

\section{Conclusions}

Thus, the way how to evaluate and at what optimum bottom-hole pressure it is advisable to exploit the deposit lateral horizontal hole with maximum "water-free" production rate are described in the paper. The calculations carried out and analysis of the graphs of additional oil and liquid production dependence on bottom-hole pressure, graphs of production dynamics and water encroachment, it was concluded that 3 groups of drilling (kickoff) of lateral holes $(\mathrm{KLH})$ should be distinguished: with high forecasted starting water encroachment $(>90 \%)$, average starting water encroachment (about $80 \%$ ), and low starting water encroachment (about 20-50\%). The distinguished 3 groups allow applying the differentiation of parameters, for which optimum bottom-hole pressure parameters for each drilling group were found in the paper.

\section{References}

1. B. Theuveny, D. Mikhailov, P. Spesivtsev, A. Starostin, A. Osiptsov, M. Sidorova, V. Shako, Integrated approach to simulation of near-wellbore and wellbore cleanup, SPE Annual Technical Conference and Exhibition (2013)

2. P. Spesivtsev, A. Kharlashkin, K. Sinkov, Study of the transient terrain-induced and severe slugging problems by use of the drift-flux model, SPE Journal (2017)

3. P. Spesivtsev, et al. Predictive model for bottom-hole pressure based on machine learning, Journal of Petroleum Science and Engineering 166, 825-841 (2018)

4. M.Ahmadi, Ch. Zhangxin, Machine learning models to predict bottom hole pressure in multiphase flow in vertical oil production wells, The Canadian Journal of Chemical Engineering 97.11, 2928-2940 (2019)

5. R. Vyakhirev, Yu. Korotaev, Theory and experience of developing deposits of natural gasesb(Nedra, 1999)

6. S. Miroshnichenko, K. Sidelnikov Determination of the optimum bottom-hole pressure of the well lateral horizontal hole exploitation, Intellectual systems in production $\mathbf{1 8}$, 65-71 (2020)

7. V. Lyalin, K. Sidelnikov, R. Faizullin, The application of genetic algorithm for optimal control the oil well mode in case of one-phase flow in porous media, Applied Mathematical Sciences 15, 739-745 (2015)

8. E. Romanova, V. Sergeev, Adaptive identification of pressure recovery curve of horizontal wells with current diagnostics, News of Tomsk Polytechnic University 323, 20-25 (2013)

9. R. Khisamov, E. Suleymanov, R. Farkhullin Hydrodynamic investigations of wells and methods of processing measurement results, VNIIOENG (2000) 